\title{
Functional-Equivalent Approach in UNCITRAL Electronic Commerce Legislation
}

\author{
Lyu Guomin \& Zhou Shengmian \\ Law School Jinan University \\ Law School Jinan University \\ Guangzhou, China \\ llguomin@sina.com
}

\begin{abstract}
This paper sums up the legislative value of the functional-equivalent approach by analyzing its specific application in the electronic commerce legislation, and believes that the approach can better deal with traditional legal obstacles which the indirect electronic commerce faces. However, with the rapid development of direct electronic commerce, the limitations of the functional-equivalent approach have begun to magnify. On the basis of the limitations, the authors argue that the legislation of electronic commerce shall be transformed from the dual-track system of functional equivalence to a new stage of uniform law appropriate for the traditional and electronic commerce ultimately.
\end{abstract}

Keywords-Functional equivalence; Electronic commerce legislation

\section{INTRODUCTION}

siness activities is "paperless". Therefore, the traditional legal system based on paper documents will undoubtedly constitute a major obstacle to the development of electronic commerce. The United Nations Commission on International Trade Law (hereinafter referred to as the UNCITRAL) created a solution named "functional-equivalent approach" in the legislation of electronic commerce to settle the conflicts between the traditional law in paper-based environment and electronic commerce practice based on paperless electronic environment. The approach analyzes various functions of traditional paper-based forms and believes that the electronic forms shall be endowed with the same legal effect if they can implement such functions. The "functional-equivalent approach" has been applied in the electronic commerce legal documents enacted by the UNCITRAL and the domestic electronic commerce law stipulated by countries around the world, which solves some basic problems such as the writing, signature and original in the electronic commerce legislation.

\section{ORIGIN AND APPLICATION OF FUNCTIONAL- EQUIVALENT APPROACH}

At the 25th session of the UNCITRAL in 1993, the committee unanimously agreed that there was a necessity to discuss the legal issues of electronic data interchange (hereinafter referred to as EDI) in view of the fact that the use of EDI had already formed and developed rapidly at that time. The working group focused on discussing the functions performed by using paper and other medium, regardless of

Fund Project: National Social Sciences Fund Project entitled Research on UN Electronic Commerce Legislative Technique and Reference (No. 17BFX146).

Lyu Guomin, JSD, Associate Professor of Jinan University Law School

Zhou Shengmian, Master of Laws of Jinan University.. whether the data was sent as information or stored as computer records, and established that the medium other than paper to record data had the same legal value as the data applied in traditional paper documents. The working group realizes that it may be appropriate to extend the definition of "writing" to EDI technology under the circumstance that the use of EDI arising from written requirements prescribed by the national law is unrestricted, which is called the "functionalequivalent approach" contributing to meet the requirements by electronic means. It is the first time that the concept of functional equivalence has been proposed by the UNCITRAL.

Since then, the EDI working group has exclusively compiled the uniform rules on the legal aspects of EDI in the 26th to the 28th sessions. The committee discussed and revised the provisions of draft uniform rule, and many countries and international organizations made suggestions and comments. Finally, the Model Law on Electronic Commerce 1996 is formed, which is the first time that the UNCITRAL has officially adopted the functional-equivalent approach in the legislation. Articles 6-8 of the Model Law use the functional-equivalent approach to solve the three problems of "writing", "signature" and "original".

1. Writing. - Article 6 of UNCITRAL Model Law on Electronic Commerce stipulates that "where the law requires information to be in writing, that requirement is met by a data message if the information contained therein is accessible so as to be usable for subsequent reference". In other words, the function of "writing" is simply to ensure that the information contained can be accessible in the future. If the data message can implement the function, it will be the functional equivalence of paper. Since the data message and paper form are different qualitatively, they cannot substitute each other completely. The legal requirement for the validity of data message in writing is only an equivalent-functional requirement. In fact, only if the data message has the function that the information contained can be accessible for the use of subsequent reference, it is equivalently considered to be the writing of the data message.

2. Signature. - Article 7 of UNCITRAL Model Law on Electronic Commerce also adopts the functional-equivalent approach to stipulate the electronic signature issues: "where the law requires a signature of a person, that requirement is met in relation to a data message if (a) a method is used to identify that person and to indicate that person's approval of 
the information contained in the data message; and (b) that method is as reliable as was appropriate for the purpose for which the data message was generated or communicated, in the light of all the circumstances, including any relevant agreement. Paragraph 1 applies whether the requirement therein is in the form of an obligation or whether the law simply provides consequences for the absence of a signature." That is to say, as long as the data message has the function of confirming the identity of the party in accordance with the writing content and his approval of information, it is equivalently considered to be the signature of the data message.

3. Original. - Article 8 of UNCITRAL Model Law on Electronic Commerce stipulates that if the information contained in an electronic communication and data message assures the integrity from the time when it was first generated in the final form and the information is capable of being displayed to the person to whom it is to be presented, it is believed that the content of the communication or contract is the original. Similarly, the function of original in paper form to make the recorded words reliable and be provided at any time is equivalent to that in the form of data message.

The UNCITRAL enacted the "compliance with a requirement for a signature" in article 6 of the Model Law on Electronic Signatures 2001, and the "formal requirements" in article 9 of the United Nations Convention on the Use of Electronic Communications in International Contracts 2005 which further improved articles 6 and 7 of the Model Law on Electronic Commerce. The UNCITRAL Model Law on Electronic Transferable Records 2017 stipulates the application of functional-equivalent approach in a whole chapter. Chapter two, "Provisions of Functional Equivalence", not only stipulates two problems of writing and signature but also apply the functional-equivalent approach to new fields such as "transferable records" and "control" etc., which greatly enriched the theory and practice of "functional equivalence".

4. Transferable Records. - The legal effect of electronic transferable records in the current legal system is undoubted; however opinions on whether the nature of electronic transferable records is payment orders or instruments still distinguish. In order to endow electronic transferable records with the legal effect and promote the application of electronic transferable records in commercial practice, the UNCITRAL attempts to regulate the electronic transferrable records through functional-equivalent approach and focuses the functions of transferrable records on three aspects, including that the loaded information shall indicate that the electronic information equals to the transferrable records functionally, and the electronic record is unitary and under control. According to article 9 of the UNCITRAL Model Law on Electronic Transferable Records regarding the use of transferrable documents or instruments, where the law requires a transferable document or instrument, that requirement is met by an electronic record if (a) the electronic record contains the information that would be required to be contained in a transferrable document or instrument; and (b) a reliable method is used: (i) to identify that electronic record as the electronic transferable record; (ii) to render that electronic record capable of being subject to control from its creation until it ceases to have any effect or validity; (iii) to retain the integrity of that electronic record.

5. Control and Endorsement. - With respect to the possession of instruments, the UNCITRAL uses the concept of control to perform functional equivalence. When using a reliable way to establish the control of the record and recognize the person in control, the functional equivalent of possession is realized. According to article 10 of the UNCITRAL Model Law on Electronic Transferable Records, where the law requires the possession of a transferable document or instrument, the requirement is met with respect to an electronic transferable record if a reliable method is used: (a) to establish exclusive control of that electronic transferable record by a person; and (b) to identify that person as the person in control. Where the law requires transfer of possession of a transferrable document or instrument, that requirement is met through the transfer of control over the electronic transferable record. The provisions of endorsement is relatively easy, and according to article 16 of the UNCITRAL Model Law on Electronic Transferable Records, where the law requires or permits the endorsement in any form of a transferable document or instrument, that requirement is met with respect to an electronic transferable record if the information required for the endorsement is included in the electronic transferable record and that information is complaint with the requirement set forth in article 7 (writing) and article 8 (signature).

The "functional-equivalent approach" has not only been applied in the electronic commerce legislation of the UNCITRAL but also adopted by many countries when formulating the domestic law of electronic commerce. Among the 196 countries and territories counted by the UNCITRAL, 68 countries and regions have enacted domestic law on electronic commerce on the basis of the Model Law on Electronic Commerce and the Model Law on Electronic Signatures, and 20 countries and regions have already signed, approved or implemented the Convention on Electronic Communications. It can thus be seen that, on one hand, the functional-equivalent approach has been universally recognized and applied in the international and domestic electronic commerce legislation; on the other hand, we must acknowledge that equivalence and equality are different after all. The data message cannot be equivalent to the paper document because it has different nature and cannot fulfill all the possible functions of the paper document. Therefore, the scope of the application of the functional-equivalent approach is limited and even in its applicable field such as writing, signature, original and transferable record, etc., the traditional rules are not automatically applied without selection. 


\section{VAlUE AND CHALlENGES OF FUNCTIONAL- EQUIVALENT APPROACH}

It should be mentioned that the use of the functionalequivalent approach has successfully solved some basic problems of electronic commerce in traditional law, connecting the electronic commerce and traditional law, which not only saves legislative resources to make existing law adaptable to new situations and technologies arising in the electronic era, but also adapts to the abstractness of law. To sum up, the legislative value of the functional-equivalent approach is mainly reflected in the following three aspects:

1. The functional-equivalent approach serves as a bridge connecting the traditional law and electronic commerce. - As it only stipulates that the new situations in the electronic commerce are regarded as meeting the requirements in the traditional law, the use of functional-equivalent approach in the electronic commerce legislation solves problems essentially within the framework of traditional law, which connects the traditional law and new environment to develop the advantages of traditional law. The reason why the electronic commerce has caused problems which the traditional law cannot adjust is that electronic commerce is based on invisible data message. The traditional law in paperbased environment conflicts with the paperless electronic environment, so functions cannot be fully implemented due to the lack of basic environment which the traditional law relies on. Under this circumstance, the functional-equivalent approach stipulates the basic problems that traditional law depends on such as writing, signature, original, etc., solving problems that affect the application of the traditional law to the electronic commerce, which makes it possible to apply the electronic commerce to the traditional law in paper-based environment.

2. The functional-equivalent approach simplifies the electronic commerce legislation. - Because the use of functional-equivalent approach only requires a connection between electronic commerce and the traditional law in paperbased environment, the electronic commerce legislation of functional-equivalent approach does not establish new legal system to regulate new issues from the concept to the rights and obligations of both parties, which saves lots of legislative resources and can quickly respond to changes in electronic commerce practice and technologies. Once the relationship between two parties cannot be adjusted by the existing law due to the changes in technology, other legislative approaches are considered.

3. The functional-equivalent approach maintains the adaptability and compatibility with the advance of technology. - Law making requires perspectiveness, so the legislation needs to advance ahead of current social development level. However, the perspectiveness of legislation is limited after all, and the development of science and technology gets faster and faster in the era. The artificial intelligence, automatic driving and other technologies which were beyond people's imagination several years ago have become urgent issues for legislation nowadays. It is difficult to foresee how the electronic commerce will develop in the future, and it may cause a waste of legislative resources and the failure to achieve the prospective legislative goals if blindly enacting legislation to create a new legal system for new technologies which are not currently available. Using the functionalequivalent approach and the principle of technology neutrality can connect the electronic commerce and traditional law to ensure the emerging technology to gain legal status and abide by law, which is of great significance to encourage the development, innovation and commercial application of electronic commerce technology, as long as it has the relevant function which corresponds to the existing legal requirements regardless of the emerging technology. Law is an abstract product of generalization, the language of which is abstract and can be applied to different situations. Therefore, it is inherently more compatible. The use of functional-equivalent approach enables the abstractness of law to be compatible with new situations that arise in the electronic commerce and maximize the abstractness of law itself.

The "functional-equivalent approach" was formed in the 1990s, when electronic commerce activities were mainly indirect electronic commerce. The transaction form has changed compared with traditional business activities but the essence of transaction has not changed. Challenges of the traditional law that the electronic commerce faces is the formal obstacles. Therefore, the problems can be solved basically only by finding a bridge for connection or transition. The functional-equivalent approach is the bridge that can better connect the electronic commerce with the traditional law, and eliminate obstacles of applications of electronic commerce activities. However, since the beginning of the $21 \mathrm{st}$ century, due to the development of internet technology, electronic commerce has entered into a deeper level and resulted in more direct electronic commerce, which are not simply different forms of transaction from the traditional business activities. Instead, it is a new type of social relationship and there is no corresponding applicable legal system in the traditional legal system. As a result, the limitations of the functional-equivalent approach appear quickly and face the following new challenges.

1. The development of technology has produced new social relations without equivalents. - In the last century, electronic commerce was still in the early stage of development and legal relations between the parties were within the scope of the existing legal relationship, which was different in forms. Therefore, using the functional-equivalent approach endowed the data messages and traditional varieties of writings with the same legal effect, which can well incorporate electronic commerce into the scope of law. However, with the explosive progress of science and technology and the development of Internet in the 21st century, things that have not been stipulated in existing laws gradually emerge in electronic commerce, which exist only in the electronic environment rather than the paper-based environment. Under the circumstance, it is naturally impossible to use the functional-equivalent approach to incorporate new things into the traditional legal management by equating new things with the existing ones due to the lack of counterparts. The functional-equivalent approach endows data messages with the same legal effect as traditional paper documents, but it cannot be used without corresponding paper 
counterparts. The emergence of electronic commerce certification authorities established to solve problems of distrust between the parties, such as the certificate authority and website certification authority, has created multiple relationships beyond the existing legal relationship. The emergence of various transaction assurance agencies and payment platforms also result in new social relationships that did not exist in the past, making the functional-equivalent approach impossible to solve problems arising from the new relationships. As the functional-equivalent approach requires the existence of equivalents, the new social relations arising from the development of technology cannot be adjusted through the approach.

2. The concept of electronic commerce has changed in the electronic era. - Another challenge that the functionalequivalent approach faces is that people's perceptions of data messages have changed and the paperless concept has been deeply rooted among the people, and all walks of life have begun to change from paper documents to data messages. In this case, if the use of the functional-equivalent approach in the electronic commerce legislation was to avoid confusion about the effectiveness of electronic commerce and the tendency of recommendation of using data messages, the adaptation to the electronic era has gradually changed people's concept of electronic commerce. Although the electronic commerce legislation has solves the possible legal effects of new signature technology through the functional-equivalent approach, it may be redundant to use functional-equivalent approach to stipulate that data messages and paper documents have the same validity under the circumstance that the impact of electronic era on people deepens and they have consensus on the recognition of data messages.

3. The functional-equivalent approach has shifted the focus of electronic commerce legislation. - Overemphasis on the functional-equivalent approach may cause bias of the electronic legislation emphasis and ignore changes of electronic environment in the mind of people, not demonstrating the legal status of electronic environment in reality but making the electronic commerce legislation a subsidiary of traditional legislation instead. Legislators of electronic commerce have focused on the search for the functions of traditional law and standard of functional equivalence, while ignoring the issue of revising the electronic environment in the civil and commercial law. In the latest identity management issues of the UNCITRAL, some people point out that the boundaries of electronic identities are undoubtedly wider than traditional ones in the electronic era and it may not achieve good results using the functionalequivalent approach. In addition, over reliance on functionalequivalent approach in electronic commerce legislation will make people think that law is divided into traditional law and equivalent provisions of traditional law. Electronic legislation is a separate part from the traditional law, which shifts the focus of electronic commerce legislation and postpones the transition process of the commercial law into the electronic era.

\section{CONCLUSION}

The functional-equivalent approach is a legal method to connect the electronic environment with traditional law and a temporary method by its nature. With the rapid proliferation of technologies which were considered not be accepted in the past few years, such as mobile payment and cloud storage, the concepts of people have changed dramatically. The paperbased environment was the mainstream and the electronic environment only occupied a secondary position in the 1990s when countries began to implement electronic commerce legislation and the functional-equivalent approach can better solve legal obstacles that electronic commerce faced as a transitional method, while the status of electronic environment in the concept of people is quite high nowadays, becoming the mainstream even beyond the paper-based environment. Under this circumstance, whether it is the formulation and revision of traditional law or electronic commerce law, the impact of the electronic environment on the law should be taken into consideration and the legislation should be unified. Compared to the legislative mode of dual tracks in the system of "functional equivalence" of electronic and paper-based environment, the unified legislation can not only better reflect the substantial similarities between them but also reduce the confusion in the application of the law.

\section{REFERENCE}

[1] See UNCITRAL Commission 25th Session A CN.9 373, pp12-16.

[2] Li Xiazhen, Legislation of Electronic Instruments under the Perspective of Equivalency, 5 Journal of Graduate School of Chines Academy of Social Sciences (2013).

[3] See UNCITRAL Working Group IV A/CN.9/WG.IV/WP.139/Add.1Draft Model Law on Electronic Transferable Records, para 1-25.

[4] See UNCITRAL Working Group IV A/CN.9/WG.IV/WP.139/Add.1Draft Model Law on Electronic Transferable Records, para 26-43.

[5] See UNCITRAL Working Group IV A/CN.9/WG.IV/WP.139/Add.2Draft Model Law on Electronic Transferable Records, para 25-30.

[6] UNCITRAL, OVERVIEW OF THE STATUS OF UNCITRAL CONVENTIONS AND MODEL LAWS http://www.uncitral.org/pdf/english/TAC/Status/Overview-StatusTable.pdf (Last visited on April 7, 2018)

[7] Sun Zhanli, On the Fundamental Principle of the Electronic Commerce Law: under the Perspective of Global Electronic Commerce Legislation, 3 Modern Law Science (2008).

[8] Zhou Diefei, Research on the Principle of Functional Equivalence in Electronic Commerce Legislation, Master Dissertation of Hunan Normal University (2010).

[9] Gao Fuping \& Yu Difei, Solutions to that Electronic Record Is Equivalent to Paper Evidence: on the Limitation of the Electronic Signature Law, 11 Law Science (2004).

[10] Jose Angelo Estrella Faria: E-Commerce and International Legal Harmonization: Time to Go beyond Functional Equivalence [J]. South African Mercantile Law Journal, 2004, Vol. 16:529-555. 